\title{
Interactive comment on "Environmental dynamics since the last glacial in arid Central Asia: evidence from grain size distribution and magnetic properties of loess from the Ili Valley, western China" by Yue Li et al.
}

\section{Anonymous Referee \#2}

Received and published: 25 July 2017

Linguistic issues: Lines 37-42: A lack of correlation between EM1 proportions and GISP $\delta 180$ values at the millennial scale, combined with modern weather data, suggests that Arctic polar front predominates in the Ili Basin and the Kyrgyz Tian Shan piedmont during cold phases, which leads to the dust transport and accumulation of loess deposits, while the shift of mid-latitude westerlies towards the south and north controls the patterns of precipitation/moisture variations in this region. Reviewer's note: a lack of correlation between $A$ and $B$ means $C$ was dominant? It implies that there are no other possibilities $(D, E, \ldots)$. Even worse, is "while the shift of the mid-latitude 
westerlies ....controls patterns of precipitation/moisture ..." corresponding to or with "shift of the Arctic polar front controls the temperature patterns of wind strength"? If so, you have to say so.

Lines 42-44: Comparison of EM1 proportions with Northern Hemisphere summer insolation clearly illustrates local insolation-based control on wind dynamics in the region, and humidity can also influence grain size of loess over MIS3 in particular. Reviewer's note: to me (this reviewer), the logic relationship between these two sentences are not traceable at all. "local insolation-based control on wind dynamics": what does this mean?

Lines 55-60: The relative influence and intensity of these major climate subsystems have varied across the latitudinal and longitudinal range of Central Asia through time. Thus identification of the predominant climate regimes in a certain region is a crucial precondition for tracing paleoclimatic evolution. Reviewer's note: (1) relative influence? Maybe relative importance. (2) The first sentence continues its SPECIFIC tone (i.e., Central Asian), but the second sentence turns to a general tone (i.e., a certain region). To me (this reviewer), it is misleading.

Lines 66-72: While loess in Central Asia has (....) increasingly formed the focus of loess research, as yet the forcing mechanisms and the climatic conditions responsible for loess-paleosol sequences formation are ambiguous, and the paleoclimatic evolution recorded by these loess deposits in this region is not systematically understood. Reviewer's note: to me (this reviewer), "increasingly formed the focus", "the forcing mechanisms... are ambiguous", and "not systematically understood"are all belong to "expression inadequacies".

Lines 78-81: Climatic teleconnections, especially between the North Atlantic and East Asian Monsoon regions, are likely to have been recorded within the Central Asian loess. As yet, however, the region so far largely lacks data by which the role and contribution of the central parts of the Eurasian continent, as an environmental bridge,

\section{CPD}

Interactive comment
Printer-friendly version

Discussion paper 
can be elucidated. Reviewer's note: to me (this reviewer), there is a logic gap in this statement. I mean that you (authors) may have to bring the environmental bridge to the front so that the importance of Central Asia in documenting the teleconnections is pronounced first.

FURTHER NOTES: MY SPECIFIC "LINGUISTIC COMMENT" STOPS HERE AND OF COURSE THERE ARE MORE LINGUISTIC ISSUES. THIS PAPER IS READABLE, BUT THE WRITING SHOULD BE GREATLY IMPROVED.

Other suggestions Magnetic Susceptibility 1.1. "Low susceptibility in paleosols and high susceptibility in loess units" were sufficiently documented in Alaskan loess and in Siberian loess and Professor Liu Xiuming is a leading scientist on this. Please see if his works and propositions can help you. 1.2. The coarse particle-association of high susceptibility can be tested simply by measuring the susceptibility of different particlesize fractions. This can be done on selected samples and the data of the selected samples may elevate your confidence of interpretation. 1.3. If I were the author, I would have completely excluded susceptibility portion from this paper and may (just may) write a separate paper on magnetic susceptibility.

Particle Size 2.1. You need a comprehensive and streamlined review on existing literature dealing with interpretation of loess particle size. The literature review can be either "school division-based" or time-based (earlier time and later time) or countrybased (west and China). 2.2. After the expected review is properly done, you may delete those insignificant references (I mean that you cited two many and that many of them may be insignificant). 2.3. Since you heavily rely on Vandenburghe (2013) for EM1, EM2, and EM3 arguments, you are strongly suggested to provide a complete and concise re-statement of Vandenburghe (2013) in debating pros and cons of EM1, EM2, and EM3 for representing aolian dynamics. If he was so sure and nobody else was at his odd, your application of EM1, EM2, and EM3 to interpreting aolian dynamics may be more acceptable. If his argument was case-dependent, you have a harder task to establish your case though. 2.4. I am wondering if the cumulative particle-size curve 
does show a statistically meaningful break between EM1 and EM2 and also a break between EM3 and EM2? If it does not, should your reliance on Vandenburghe (2013) be questionable? What I try to say is: if you can confidently justify the acceptance of EM1, EM2, and EM3 for representing aolian dynamics, you do have a case here. Otherwise, your opponents can always argue that: those coarse particles may have indeed locally sourced, but those fine particles can either be remotely (high-elevation) sourced or locally (near-surface) sourced.

Questions for 5.3 Aeolian dust dynamics in eastern Central Asia: links to atmospheric systems Lines 440-447: Central Asia is variably influenced by the Asian monsoon from the south (Dettman et al., 2001; Cheng et al., 2012), the mid-latitude westerlies (Vandenberghe et al., 2006), the Siberian high-pressure systems from the northeast (Youn et al., 2014), and the polar front from the north (Machalett et al., 2008). However, by virtue of its geographical position, most of these climate influences can be excluded for the lli Valley since it is sheltered to the northeast, east and south. The Asian high mountains largely inhibit the intrusion of Asian (Indian and East Asian) monsoons to the region, and the influence of the Siberian High (An, 2000) has been shown to decrease westward from the CLP (Vandenberghe et al., 2006). Reviewer's note: Downplaying Asian monsoons may be acceptable since the Yili Valley is indeed blocked by the Tianshan Mountains on the south. But, downplaying Siberian high-pressure system $(\mathrm{SibH})$ is not well justified. Yes, SibH is weakening away from its center, but you cannot say that the Yili Valley was beyond the SibH influence. Furthermore, your favored "polar front" is actually also blocked by high mountains on the north. If polar front was indeed the major player, you may have to provide modern climate backgrounds in which strong polar front interacted with the prevailing westerly flow to stimulate dust storms in the Yili Valley.

Lines 448-456: Modern satellite data indicates that dust storm development in lli river valley is closely linked with southward-moving high-latitude air masses (Ye et al., 2003). Karger et al. (2016) provided a detailed picture of the westerlies for the Ili Basin, 
in which a rain belt gradually migrated towards the south and north in autumn and summer, respectively. According to this scenario, enhanced evaporation coupled with strengthened westerly winds would bring more humid and warm air masses to Arid Central Asia (ACA) during the Holocene (Zhang et al., 2016). Therefore, based on our grain-size observations, we argue that the Arctic polar front, intruding southward in the winter and retracting northward in summer (Machalett et al., 2008), most likely increased the frequency and strength of cyclonic storms, leading to dust transport and the accumulation of loess deposits during cold phases when it predominated in the lli Basin and along the Kyrgyz Tian Shan piedmont. Reviewer's note: I (this reviewer) failed to see the linkage between "souward-moving high-latitude air masses" and "migrated rain belt". I also failed to see the linkage between "enhanced evaporation" and "strengthened westerly winds". Consequently, I failed to see the logic of your reasoning: the Arctic polar front, intruding southward in the winter and retracting northward in summer (Machalett et al., 2008), most likely increased the frequency and strength of cyclonic storms during cold phases. At least, you have to say more about the logic of your reasoning.

Interactive comment on Clim. Past Discuss., https://doi.org/10.5194/cp-2017-50, 2017.

Interactive

comment

\section{Discusion paper}

